\title{
Preexisting radiological interstitial lung abnormalities are a risk factor for severe radiation pneumonitis in patients with small-cell lung cancer after thoracic radiation therapy
}

Fangjuan $\mathrm{Li}^{1,2}$, Ziyang Zhou ${ }^{3}$, Ailu Wu ${ }^{2}$, Yong Cai ${ }^{2}$, Hongyu Wu ${ }^{2}$, Ming Chen ${ }^{4,5^{*+}}$ and Shixiong Liang ${ }^{2^{*+}}$

\begin{abstract}
Background: Previous studies reported that patients with preexisting radiological interstitial lung abnormalities (ILAs) were more susceptible to developing radiation pneumonitis (RP) after thoracic radiation therapy (TRT). The present study aimed to evaluate the incidence and predictors of RP after TRT in patients with small-cell lung cancer (SCLC) with or without preexisting radiological ILAs.

Methods: A total of 95 consecutive patients with SCLC between January 2015 and December 2015, who were treated with thoracic intensity-modulated radiation therapy at Shanghai Pulmonary Hospital,Tongji University School of Medicine, were analyzed. The diagnosis of ILAs was reviewed by two experienced thoracic radiologists based on the pretreatment high-resolution computed tomography imaging, such as honeycombing, subpleural reticular opacities, ground-glass opacity, and traction bronchiectasis. Univariate and multivariate analyses were used to assess the correlation of clinical factors, preexisting radiological ILAs, and dose-volume histogram-based dosimetric parameters with RP.

Results: Fifteen (15.8\%) patients had preexisting radiological ILAs. The incidence of $\geq$ grade 2 and 3 RP at 1 year was $27.1 \%$ and $12.7 \%$ in the entire cohort, respectively. Preexisting radiological ILAs were associated with an increased risk of $\geq$ grade 2 RP $(50.0 \%$ in ILAs + vs $23.3 \%$ in ILAs-, $P=0.017)$ and $\geq$ grade 3 RP (35.8\% in ILAs + vs 8.9\% in ILAs-, $P=0.005$ ) at 1 year. Preexisting radiological ILAs and smoking history ( $\geq 40$ packyears of smoking) were significant predictors of $\geq$ grade 3 RP in multivariate analysis $(P=0.023$ and 0.012 , respectively).
\end{abstract}

Conclusions: Preexisting radiological ILAs and smoking history ( $\geq 40$ pack-years of smoking) are associated with an increased risk of $\geq$ grade 3 RP after TRT in patients with SCLC.

Keywords: Interstitial lung abnormalities-radiation pneumonitis-radiotherapy-small-cell lung cancer

\footnotetext{
*Correspondence: chenming@zjcc.org.cn; shixliang@vip.sina.com

${ }^{\dagger}$ Equal contributors

${ }^{4}$ Department of Radiation Oncology, Zhejiang Cancer Hospital, East Banshan

Road, Gongshu District, Hangzhou, People's Republic of China

${ }^{2}$ Department of Radiation Oncology, Shanghai Pulmonary Hospital,Tongji

University School of Medicine, Zhengmin Road, Yangpu District, Shanghai

200433, People's Republic of China

Full list of author information is available at the end of the article
}

(c) The Author(s). 2018 Open Access This article is distributed under the terms of the Creative Commons Attribution 4.0 International License (http://creativecommons.org/licenses/by/4.0/), which permits unrestricted use, distribution, and reproduction in any medium, provided you give appropriate credit to the original author(s) and the source, provide a link to the Creative Commons license, and indicate if changes were made. The Creative Commons Public Domain Dedication waiver (http://creativecommons.org/publicdomain/zero/1.0/) applies to the data made available in this article, unless otherwise stated. 


\section{Background}

Small-cell lung cancer (SCLC) accounts for approximately $10-15 \%$ of the total number of cases with lung cancer [1]. The standard treatment for patients with limited-stage SCLC is combined chemotherapy (using platinum-based regimen) and thoracic radiation therapy (TRT) [2]. The outcomes are poor even in the earlystage disease, with a median survival of 19-30 months after curative-intent treatment and 2-year survival of less than $60 \%[3,4]$.

Symptomatic radiation pneumonitis (RP) is a major complication occurring in $15 \%-40 \%$ of the patients with lung cancer receiving concurrent chemoradiotherapy [5]. Previous studies demonstrated that the dose-volume parameters, such as $V_{20}$ (percentage of the lung volume receiving $\geq 20 \mathrm{~Gy}$ ), $V_{5}$ (percentage of the lung volume receiving $\geq 5 \mathrm{~Gy}$ ), mean lung dose (MLD), treatment factors (e.g., sequential/concurrent chemotherapy schedules), tumor factors (e.g., disease location in the lower lung, tumor size), and patient factors (e.g., smoking history, presence of comorbidity), are predictors for developing clinically evident (grades 2-3) radiation pneumonitis. These factors were correlated with RP in patients with lung cancer [5-12].

Interstitial lung abnormalities (ILAs) have a higher incidence in patients with lung cancer compared with the general population [13-15]. Radiographic ILAs were present in $14 \%$ of treatment-naive patients with advanced non-small-cell lung carcinoma (NSCLC) [16]. The widespread use of high-resolution computed tomography (HRCT) in clinical applications has facilitated the detection of ILAs in asymptomatic and undiagnosed individuals [17]. Previous studies reported that patients with preexisting radiological ILAs were more susceptible to developing RP after TRT or stereotactic body radiotherapy (SBRT) [18-21]. Most of these studies were based on patients with NSCLC. The correlation between preexisting radiological ILAs and RP in patients with SCLC is still unclear. Consequently, this single-institution study was conducted to assess all factors as predictors of RP in patients with SCLC based on radiological ILAs, clinical parameters, and dose-volume histogram-based dosimetric parameters.

\section{Methods}

\section{Patients}

From January 2015 to December 2015, 95 consecutive patients diagnosed with SCLC by histology or cytology and treated with TRT were enrolled in the present study. The inclusion criteria were as follows: 1) Karnofsky performance status score $\geq 70$, and could endure a definitive RT at a total dose of $\geq 50$ Gy [2.0 Gy/(fraction - day)]; 2) RT with concurrent or sequential chemotherapy; 3) follow-up time of more than 6 months for patients without RP; 4) thoracic computed tomographic (CT) images available for evaluation before and after RT. The exclusion criteria were as follows: 1 ) age $\geq 80$ years; 2 ) lobectomy; 3) hypofractionated radiation (>2.0 Gy/fraction); and 4) SBRT. Informed consent was obtained from all patients. Ethical approval was obtained from the Ethical Review Committee of Shanghai Pulmonary Hospital, Tongji University School of Medicine, China.

\section{Radiotherapy}

All patients underwent a planning CT scan and were immobilized in a supine position with their arms raised in a customized vacuum-lock mold. The simulation CT images were taken in 5-mm increments over the region of interest. Treatment planning was performed with the ADAC Pinnacle TM (Philips Medical Systems) treatment planning system. Treatments were delivered with 6 or 10 MV photons utilizing the thoracic intensitymodulated radiation therapy method on Siemens Artiste (Oncology Care Systems, Siemens Medical Solutions, CA, USA) digital linear accelerator with a multileaf collimator. A gross tumor volume (GTV) was defined as the volume of a primary tumor demonstrated by a CT scan and metastatic lymph nodes that measured $\geq 1 \mathrm{~cm}$ in the short axis. A clinical target volume was typically a 0.5 to $0.8-\mathrm{cm}$ expansion of the GTV, including the primary tumor and the drainage area of metastatic lymph nodes. A planning target volume (PTV) was defined by adding margins at the discretion of radiation oncologists (typically $0.5-1.0 \mathrm{~cm}$ for lateral margins and $1.0-2.0 \mathrm{~cm}$ for craniocaudal margins, depending on respiratory motion and patient fixation). The planning goal was to deliver the prescription dose to at least $95 \%$ of the PTV, while meeting normal tissue constraints. The total dose was $\geq 60$ Gy in limited-stage SCLC and $\geq 50$ Gy in extensivestage SCLC, generally delivered at $2.0 \mathrm{~Gy} /$ (fraction - day, five fractions per week. If the dose of lung exceeds the safety range $\left(V_{20} \leq 30 \%, V_{5} \leq 60 \%\right.$, MLD $\left.\leq 17 \mathrm{~Gy}\right)$, we will appropriately reduce the total dose.

\section{Chemotherapy}

The concurrent chemotherapy regimen mainly consisted of cisplatin and etoposide. The second choice for concurrent chemotherapy consisted of carboplatin and etoposide in patients aged $>75$ years, with a low-performance status, low renal function (creatinine clearance $<60 \mathrm{~mL} / \mathrm{min}$ ), a syndrome of inappropriate secretion of antidiuretic hormone, or other severe complications. The first-choice chemotherapy regimen consisted of $25 \mathrm{mg} / \mathrm{m}^{2}$ of intravenous cisplatin and $70-100 \mathrm{mg} / \mathrm{m}^{2}$ of intravenous etoposide on days $1-3$. The second-choice chemotherapy regimen consisted of intravenous carboplatin with an area under the curve (AUC) of 5 on day 1 and $70-100 \mathrm{mg} / \mathrm{m}^{2}$ of etoposide on days $1-3$. The dose of cisplatin, etoposide, or carboplatin in subsequent cycles was reduced by $10-20 \mathrm{mg} / \mathrm{m}^{2}$ or 
Table 1 Patient and treatment characteristics for all patients [with ILAs (ILA+) and without ILAs (ILA-)]

\begin{tabular}{|c|c|c|c|c|}
\hline \multirow[t]{2}{*}{ Characteristics } & All & $\mathrm{ILA}(+)$ & $\mathrm{ILA}(-)$ & $P$ values \\
\hline & $n=95$ & $n=15$ & $n=80$ & $\operatorname{ILA}(+)$ vs ILA(-) \\
\hline Age (year) & & & & .948 \\
\hline Mean (range) & $61(42-80)$ & $67(55-80)$ & $60(42-80)$ & \\
\hline Gender & & & & 1.000 \\
\hline Male & 85 & 13 & 72 & \\
\hline Female & 10 & 2 & 8 & \\
\hline Smoking history (pack-year) & & & & .390 \\
\hline$<40$ & 60 & 8 & 52 & \\
\hline$\geq 40$ & 35 & 7 & 28 & \\
\hline Tumor stage & & & & .885 \\
\hline \|la & 1 & 0 & 1 & \\
\hline Illa & 18 & 3 & 15 & \\
\hline $\mathrm{lllb}$ & 52 & 9 & 43 & \\
\hline IV & 24 & 3 & 21 & \\
\hline Tumor location & & & & .580 \\
\hline Upper or middle lobe & 74 & 13 & 61 & \\
\hline Lower lobe & 21 & 2 & 19 & \\
\hline Chemotherapy & & & & .650 \\
\hline Sequential & 75 & 13 & 62 & \\
\hline Concurrent & 20 & 2 & 18 & \\
\hline Chemotherapy regimen & & & & .223 \\
\hline Etoposide+cisplatin & 61 & 7 & 54 & \\
\hline Etoposide+carboplatin & 32 & 7 & 25 & \\
\hline Other drugs & 2 & 1 & 1 & \\
\hline
\end{tabular}

Abbreviations: ILAs Interstitial lung abnormalities

AUC of 1 from the planned dose when grade 4 hematologic toxicity or grade 3 nonhematologic adverse events occurred. Chemotherapy was interrupted or changed as a result of prolonged hematologic toxicity, severely elevated creatinine, pulmonary infection, or chemoradiotherapy-induced pneumonitis. Chemotherapy was principally performed in 4-6 cycles every 4 weeks. Patients with older age, stage IV, and poor lung function were considered not suitable for the concurrent chemoradiotherapy; some others were also reluctant to choose this treatment mode due to their poor endurance.

\section{Radiological ILAs evaluation based on CT}

Radiological ILAs assessment was based on pretreatment HRCT imaging with an axial slice thickness of $1 \mathrm{~mm}$ in a lung window. Reticular abnormalities, traction bronchiectasis, bilateral independent ground-glass abnormalities, honeycombing, and nonemphysematous cysts were defined as findings indicative of ILAs [17, 21, 22]. Types of ILAs were generally based on history, physical examination, chest HRCT, pulmonary function tests, laboratory tests, bronchoalveolar lavage fluid and lung biopsy. The classification was made according to the American Thoracic Society/European Respiratory Society/Japan Respiratory Society/Latin American Thoracic Association guidelines in 2011 [23]. All CT scans and types of ILAs were evaluated independently by the radiologist and physician specialized in pulmonology.

\section{Definition of RP grading}

According to the Common Terminology Criteria for Adverse Events 4.0, RP was diagnosed based on the clinical symptoms of patients and their radiographic changes on CT scans. RP was graded by several experienced radiation oncologists at the institution according to the following criteria: grade 0 , no symptom or radiographic change; grade 1 , asymptomatic and radiographic changes only; grade 2 , symptomatic but not interfering with the daily life; grade 3 , symptomatic but interfering with the daily life, and oxygen is needed; grade 4, life-threatening and ventilator support indicated; and grade 5, death. 
Table $\mathbf{2}$ Characteristics of the patients with preexisting radiological ILAs

\begin{tabular}{|c|c|c|c|c|c|c|c|c|}
\hline No. & $\begin{array}{l}\text { Age (year)/ } \\
\text { Gender }\end{array}$ & $\begin{array}{l}\text { RT dose } \\
\text { (Gy) }\end{array}$ & $\begin{array}{l}\text { Treatment } \\
\text { modality }\end{array}$ & $\begin{array}{l}\text { Grade } \\
\text { of ILAs }\end{array}$ & $\begin{array}{l}\text { Interstitial change } \\
\text { pattern }\end{array}$ & $\begin{array}{l}\text { Involvement of } \\
\text { interstitial change }\end{array}$ & Types of ILAs & $\begin{array}{l}\text { Grade } \\
\text { of RP }\end{array}$ \\
\hline 1 & $80 / \mathrm{M}$ & 50 & RT alone & Slight & Reticular opacities & Right lung & Uncertain & 2 \\
\hline 2 & $72 / \mathrm{M}$ & 50 & RT alone & Slight & Honeycombing & Right lower lobe & Uncertain & 0 \\
\hline 3 & $78 / \mathrm{M}$ & 50 & RT alone & Moderate & Reticular opacities/ honeycombing & Entire lung & $\begin{array}{l}\text { Collagen-vascular } \\
\text { diseases }\end{array}$ & 2 \\
\hline 4 & $67 / \mathrm{M}$ & 60 & CCRT & Mild & Reticular opacities & Both lower lobe & $\begin{array}{l}\text { Secondary interstitial } \\
\text { pneumonia }\end{array}$ & 3 \\
\hline 5 & $71 / \mathrm{M}$ & 60 & RT alone & Slight & Focal reticular opacities & Right lower lobe & Uncertain & 0 \\
\hline 6 & $55 / \mathrm{M}$ & 60 & RT alone & Mild & Reticular opacities & Both lower lobe & Uncertain & 3 \\
\hline 7 & $64 / F$ & 60 & RT alone & Mild & Reticular opacities & Both lower lobe & Uncertain & 2 \\
\hline 8 & $72 / \mathrm{M}$ & 60 & RT alone & Slight & Focal reticular opacities & Right lower lobe & Uncertain & 0 \\
\hline 9 & $59 / \mathrm{M}$ & 60 & RT alone & Slight & Focal reticular opacities & Right lower lobe & Uncertain & 0 \\
\hline 10 & $59 / \mathrm{M}$ & 50 & RT alone & Mild & Focal reticular opacities & Both lower lobe & Uncertain & 0 \\
\hline 11 & $59 / F$ & 60 & RT alone & Mild & Reticular opacities & Both lower lobe & Uncertain & 0 \\
\hline 12 & 64/M & 60 & RT alone & Moderate & Reticular opacities/ honeycombing & Entire lung & $\begin{array}{l}\text { Secondary interstitial } \\
\text { pneumonia }\end{array}$ & 0 \\
\hline 13 & $75 / \mathrm{M}$ & 60 & RT alone & Mild & Reticular opacities/ honeycombing & Both lower lobe & Uncertain & 3 \\
\hline 14 & 70/M & 60 & CCRT & Moderate & Honeycombing/ traction bronchiectasis & Entire lung & IPF & 0 \\
\hline 15 & $59 / \mathrm{M}$ & 64 & RT alone & Slight & Focal reticular opacities & Right lower lobe & Uncertain & 3 \\
\hline
\end{tabular}

Abbreviations: ILAs interstitial lung abnormalities, RP radiation pneumonitis, CCRT concurrent chemoradiotherapy, IPF idiopathic pulmonary fibrosis, RT radiation therapy
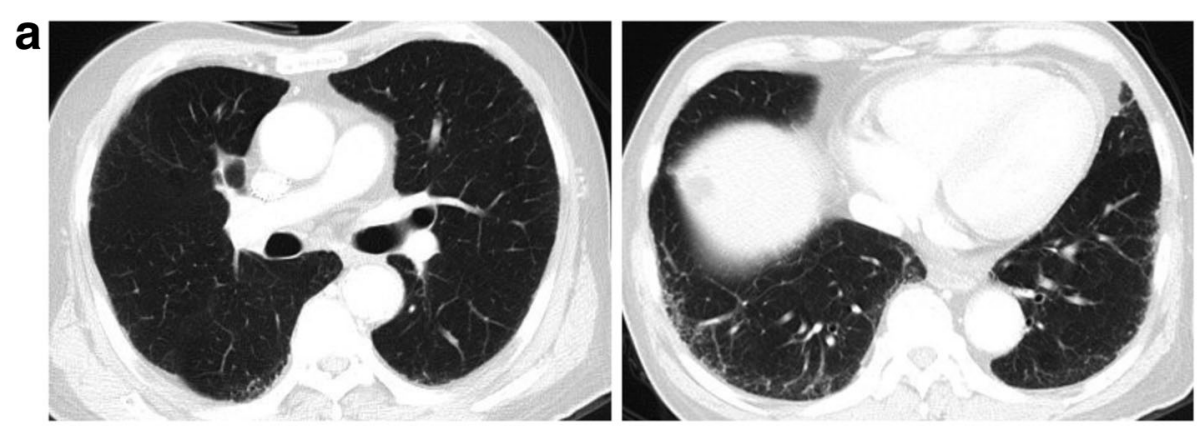

b

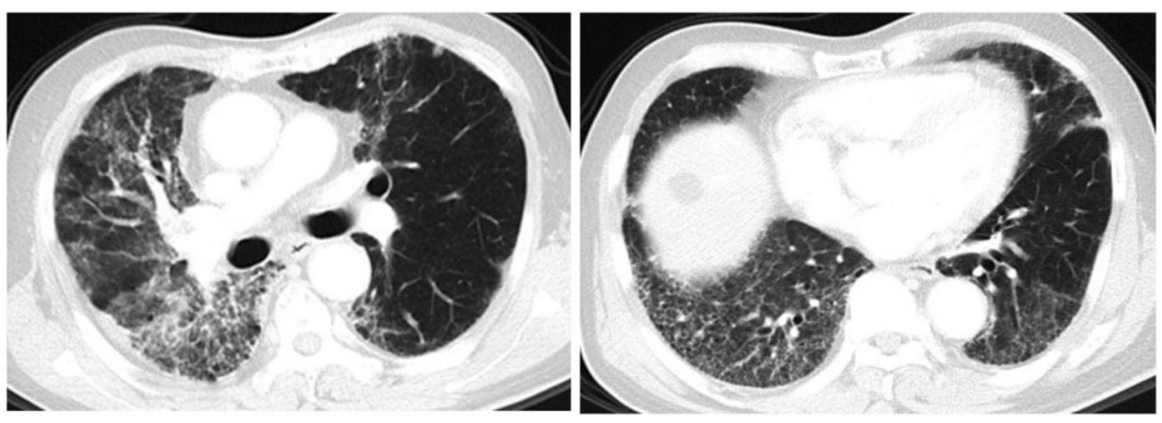

Fig. 1 A 75-year-old male with small-cell lung cancer having preexisting radiological ILAs who developed RP beyond radiation field after TRT. a Prior to RT, initial HRCT exhibited subpleural reticular opacities at levels of bilateral lower lobes. b 60 Gy in 30 fractions was delivered to a pulmonary tumor in the right upper lobe with mediastinum and right hilar lymphadenopathy. Three weeks after completing RT, the patient developed diffuse interstitial infiltration and consolidation extending beyond radiation field 


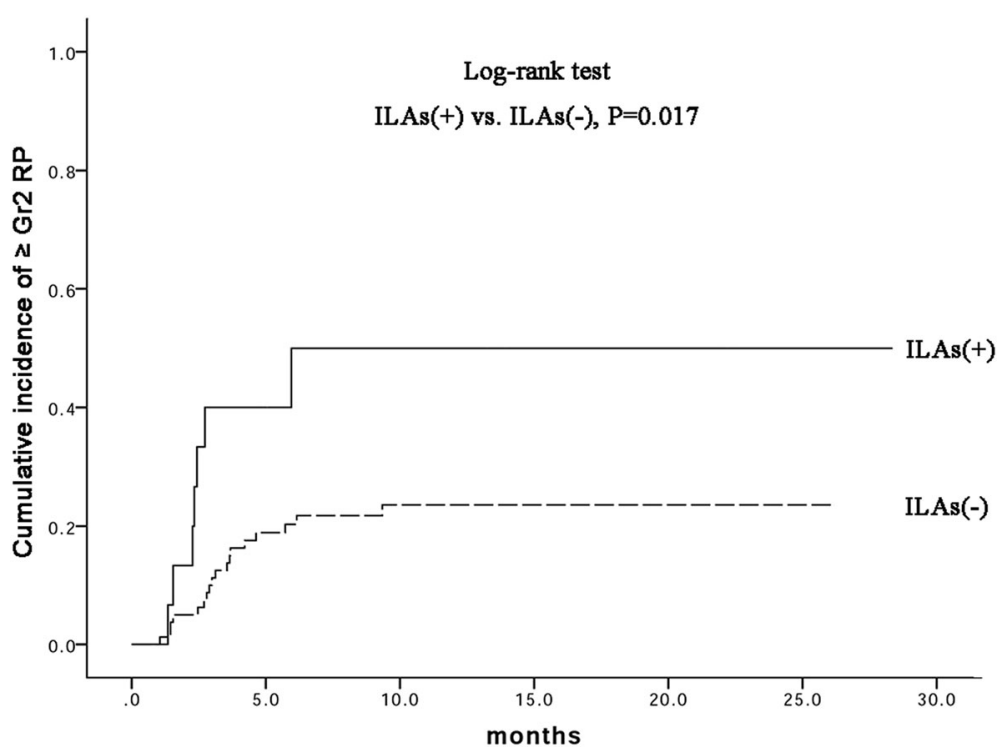

Fig. 2 Cumulative incidence of $\geq$ grade 2 RP in patients with and without ILAs

\section{Follow-up}

Patients were reevaluated at 1-2 months' posttreatment and subsequently every 3 or 6 months to check the physical status of patients. Thoracic CT was also performed at each follow-up visit. The endpoint was the incidence of $\geq$ grade 2 RP.

\section{Statistical analysis}

The variables examined were as follows: 1) patient age; 2) gender; 3) tumor stage; 4) tumor location; 5) chemotherapy regimen; 6) percentage forced vital capacity (\%FVC), forced expiratory volume in $1 \mathrm{~s}(\mathrm{FEV} 1) / \mathrm{FVC} ; 7$ ) smoking history; 8) ILAs; 9) dosimetric data: total dose, MLD, percentage of lung volume receiving $x$ Gy $(\mathrm{Vx})$, $x \geq 5,10,20,30,40$, and 50, respectively; and 10) GTV and PTV volumes.

The correlation between RP and clinical factors were analyzed using the chi-square test or continuity correction test. The Student $\mathrm{t}$ test for linear variables and Fisher exact test for categorical variables were used for univariate analysis. Multivariable logistic regression analysis was performed to evaluate the data for the correlation between clinical factors and dose-volume histogram (DVH) factors with RP. Statistical analysis was performed using SPSS

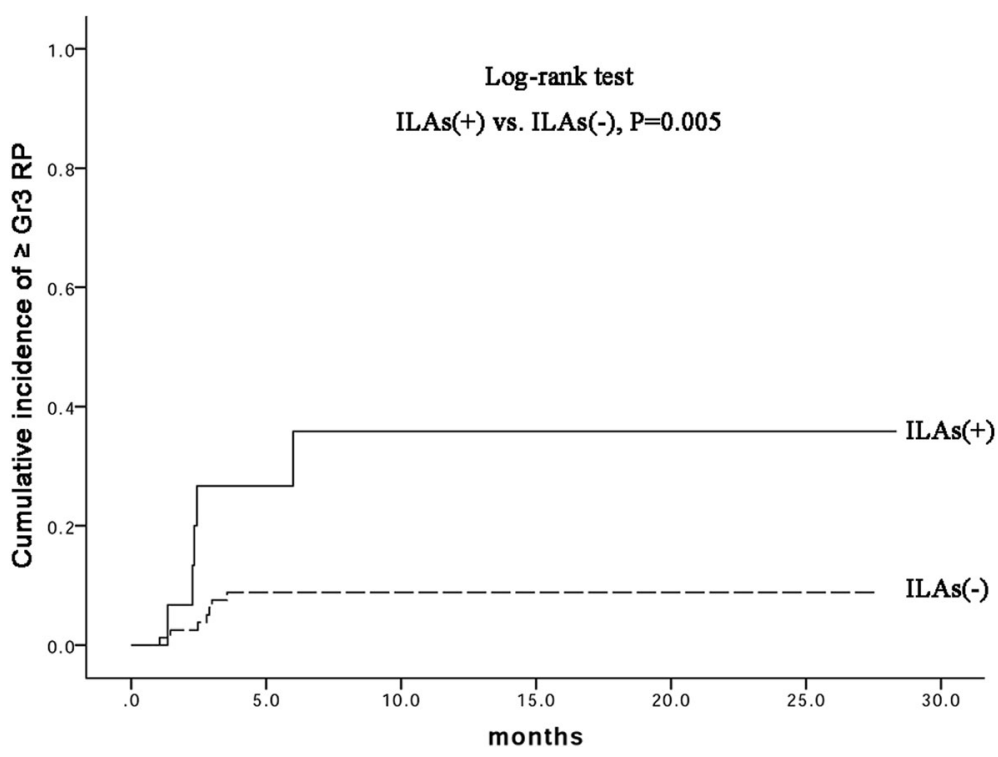

Fig. 3 Cumulative incidence of $\geq$ grade 3 RP in patients with and without ILAs 
Table 3 Correlation between clinical factors and RP by univariate analysis

\begin{tabular}{|c|c|c|c|c|c|c|}
\hline \multirow[t]{2}{*}{ Factors } & \multicolumn{3}{|l|}{$\geq$ Grade 2 RP } & \multicolumn{3}{|l|}{$\geq$ Grade 3 RP } \\
\hline & No. of RPs/Total (\%) & $x^{2} / F$ & $P$ value & No. of RPs/Total (\%) & $x^{2} / F$ & $P$ value \\
\hline Gender & & .078 & 1.000 & & 1.616 & .442 \\
\hline Male & 22/85 (25.9) & & & $12 / 85(14.1)$ & & \\
\hline Female & $3 / 10(30.0)$ & & & $0 / 10(0)$ & & \\
\hline Age (year) & & .102 & .987 & & & 1.000 \\
\hline$<70$ & 20/78 (25.6) & & & 10/78 (12.8) & .014 & \\
\hline$\geq 70$ & 5/17 (29.4) & & & 2/17 (11.8) & & \\
\hline Smoking history (pack-year) & & .537 & .464 & & 8.035 & .012 \\
\hline$<40$ & $14 / 59(23.7)$ & & & $3 / 59(5.1)$ & & \\
\hline$\geq 40$ & $11 / 36(30.6)$ & & & $9 / 36(25.0)$ & & \\
\hline Tumor stage & & 1.494 & .684 & & 3.458 & .122 \\
\hline Ila & $0 / 1(0.0)$ & & & $0 / 1(0.0)$ & & \\
\hline IIla & $3 / 18(16.7)$ & & & $0 / 18(0.0)$ & & \\
\hline$\| l l b$ & 15/52 (28.8) & & & $8 / 52(15.4)$ & & \\
\hline IV & $7 / 24(29.2)$ & & & $4 / 24(16.7)$ & & \\
\hline Tumor location & & .734 & .564 & & 1.513 & .391 \\
\hline Upper or middle lobe & 21/74 (28.4) & & & $11 / 74(14.9)$ & & \\
\hline Lower lobe & $4 / 21(19.0)$ & & & $1 / 21(0.5)$ & & \\
\hline Chemotherapy & & .177 & .674 & & .159 & .984 \\
\hline Sequential & 19/75 (25.3) & & & 10/75 (13.3) & & \\
\hline Concurrent & $6 / 20(30.0)$ & & & $2 / 20(10.0)$ & & \\
\hline Total dose (Gy) & & .748 & .592 & & 1.151 & .524 \\
\hline$<54$ & $5 / 14(35.7)$ & & & $3 / 14(21.4)$ & & \\
\hline$\geq 54$ & 20/81 (24.7) & & & 9/81 (11.1) & & \\
\hline $\mathrm{FEV}_{1} / \mathrm{FVC}(\%)$ & & .106 & 1.000 & & & 1.000 \\
\hline$<70$ & $4 / 25(16.0)$ & & & 2/25 (8.0) & .050 & \\
\hline$\geq 70$ & 6/31 (19.4) & & & $2 / 31(6.5)$ & & \\
\hline FVC (\%) & & .050 & 1.000 & & & .747 \\
\hline$<80$ & 4/23 (17.4) & & & 2/23 (8.7) & 0.858 & \\
\hline$\geq 80$ & 5/33 (15.2) & & & 1/33 (3.0) & & \\
\hline Radiological ILAs & & 3.805 & .103 & & 6.917 & .027 \\
\hline Yes & $7 / 15(46.7)$ & & & 5/15 (33.3) & & \\
\hline No & 18/80 (22.5) & & & 7/80 (8.8) & & \\
\hline
\end{tabular}

Abbreviations: $F E V_{1}$ Forced expiratory volume in $1 \mathrm{~s}, F V C$ forced vital capacity, ILAs interstitial lung abnormalities, RP radiation pneumonitis

software 22.0 for Mac. A $P$ value $<0.05$ was considered statistically significant.

\section{Results}

\section{Patients and treatment characteristics}

The characteristics of these patients are presented in Table 1 . The present study identified 15 (15.8\%) patients with preexisting radiological ILAs. No statistically significant difference was observed in age, gender, smoking history, tumor stage, tumor location, and sequential/concurrent chemotherapy schedules; different chemotherapy regimens compared patients with radiographic ILAs to those without radiographic ILAs. The presence, extent and distribution of ILAs were determined based on chest HRCT criteria in a previous study [19]. None of these patients diagnosed with clinical interstitial lung disease prior to radiotherapy. The characteristics of the patients with preexisting radiological ILAs are presented in Table 2.

\section{RP incidence}

The median follow-up time was 13.0 months (range, 3.4-28.4 months). RP was observed in 33 (34.7\%), 13 
Table 4 Correlation between dosimetric factors and RP by univariate analysis

\begin{tabular}{|c|c|c|c|c|c|c|}
\hline \multirow[t]{2}{*}{ Factors } & \multicolumn{3}{|l|}{$\geq$ Grade 2 RP } & \multicolumn{3}{|l|}{$\geq$ Grade 3 RP } \\
\hline & Without RP & With RP & $P$ value & Without RP & With RP & $P$ value \\
\hline GTV volume (mL) & $130.2 \pm 104.9$ & $122.4 \pm 83.9$ & .758 & $125.9 \pm 101.1$ & $143.6 \pm 89.2$ & .795 \\
\hline PTV volume (mL) & $401.3 \pm 205.7$ & $395.7 \pm 159.0$ & .484 & $396.6 \pm 196.7$ & $422.1 \pm 178.4$ & .933 \\
\hline MLD (cGy) & $1361.6 \pm 259.7$ & $1408.6 \pm 239.2$ & .935 & $1366.0 \pm 261.2$ & $1428.9 \pm 198.3$ & .514 \\
\hline$V_{5}$ & $48.6 \pm 9.4$ & $51.12 \pm 9.5$ & .576 & $49.0 \pm 9.4$ & $50.9 \pm 9.8$ & .730 \\
\hline$V_{10}$ & $35.8 \pm 7.1$ & $38.2 \pm 6.4$ & .925 & $36.1 \pm 7.0$ & $38.4 \pm 6.7$ & .915 \\
\hline$V_{20}$ & $23.7 \pm 4.2$ & $25.7 \pm 4.2$ & .929 & $23.9 \pm 4.2$ & $26.7 \pm 4.0$ & .919 \\
\hline$V_{30}$ & $16.6 \pm 3.8$ & $18.8 \pm 4.4$ & .565 & $16.8 \pm 4.0$ & $19.8 \pm 3.8$ & .782 \\
\hline$V_{40}$ & $12.1 \pm 3.5$ & $12.9 \pm 4.1$ & .775 & $12.1 \pm 3.6$ & $13.8 \pm 3.6$ & .335 \\
\hline$V_{50}$ & $7.7 \pm 3.6$ & $7.4 \pm 3.3$ & .534 & $7.5 \pm 3.6$ & $8.0 \pm 2.7$ & .140 \\
\hline
\end{tabular}

Abbreviations: GTV Gross tumor volume, MLD mean lung dose, PTV planning target volume, RP radiation pneumonitis

(13.7\%), $12(12.6 \%)$, and $0(0 \%)$ patients with grades $1,2,3$, and $\geq 4 \mathrm{RP}$, respectively. Radiotherapy was discontinued in one patient because of RP during radiotherapy. Representative CT images are illustrated in Fig. 1. The cumulative incidence of $\geq 2$ grade at 1 year was $27.1 \%$ (95\% confidence interval [CI]: 17.3-35.3) for all patients, $50.0 \%$ (95\% CI: 18.1-75.3) for the radiological ILA(+), and 23.3\% (95\% CI:13.1-31.9) for the radiological ILA(-). The cumulative incidence of $\geq$ grade $3 \mathrm{RP}$ at 1 year was $12.7 \%$ (95\% CI: $5.8-19.4$ ) for all patients, $35.8 \%$ (95\%CI: $6.3-60.4$ ) for the radiological ILA(+), and 8.9\% (95\% CI: 2.4-15.1) for the radiological ILA(-). Radiological ILAs were associated with increased risk of $\geq$ grades 2 and 3 RP $(P=0.017$ and 0.005, respectively; Figs. 2 and 3).

\section{Factors associated with RP}

Table 3 reveals the correlation between clinical factors and RP. In univariable analysis, radiological ILAs was not found to be a significant factor influencing $\geq$ grade $2 \mathrm{RP}$; However, the risk of $\geq$ grade $3 \mathrm{RP}$ was higher in patients with radiological ILAs $(P=0.027)$. Smoking history $(\geq 40$ pack-years of smoking) was associated with $\geq$ grade $3 \mathrm{RP}$ $(P=0.012)$. The correlation between dosimetric factors and RP is presented in Table 4. No correlation was observed between the incidence of RP and dosimetric factors. Any factor significant in univariate analysis was subjected to multivariate analysis using the Cox proportional hazards regression model. Preexisting radiological ILAs and smoking history ( $\geq 40$ pack-years of smoking) were significant predictors of $\geq$ grade $3 \mathrm{RP}$ in multivariate analysis $(P=0.023$ and 0.012 , respectively) (Table 5).

\section{Discussion}

Previous studies demonstrated that the dose-volume parameters and treatment factors are predictors for developing RP after TRT in patients with SCLC. In addition, the patient factors are also closely related to the incidences of RP. Previous studies reported that patients with preexisting radiological ILAs were more susceptible to developing severe, extensive RP after TRT or SBRT in lung tumor [18-21]. Severe ILAs was regarded as a relative contraindication in the clinical guidelines for SBRT published by the Japanese Society for Therapeutic Radiation and Oncology [19]. Most of these studies were based on patients with NSCLC. The correlation between preexisting ILAs and RP in patients with SCLC is still not clear. The present study examined the clinical and dosimetric factors as predictors of RP and evaluated the correlation between ILAs and RP. The findings revealed that the presence of preexisting radiological ILAs was also associated with increased risk of $\geq$ grade $3 \mathrm{RP}$. This was a new finding for the radiation oncologists because few studies focused on the correlation between radiological ILAs in preradiation therapy HRCT and RP in patients with SCLC. These raised the important pointers to preexisting radiological ILAs in lung cancer, increasing the chances of an "exacerbation," particularly with radiation therapy. The patients

Table $\mathbf{5}$ Correlation between factors and RP by multivariate analysis

\begin{tabular}{|c|c|c|c|c|c|c|c|c|}
\hline \multirow[t]{2}{*}{ Factors } & \multirow[t]{2}{*}{$B$} & \multirow[t]{2}{*}{ S.E } & \multirow[t]{2}{*}{ Wald } & \multirow[t]{2}{*}{ df } & \multirow[t]{2}{*}{$P$} & \multirow{2}{*}{$\begin{array}{l}\text { EXP } \\
\text { (B) }\end{array}$} & \multicolumn{2}{|c|}{$95 \% \operatorname{EXP}(B)$} \\
\hline & & & & & & & Lower & Upper \\
\hline Radiological ILAs & -1.652 & .728 & 5.154 & 1 & .023 & .192 & .046 & .789 \\
\hline Smoking history ( $\geq 40$ pack-years of smoking) & -1.828 & .731 & 6.252 & 1 & .012 & .161 & .038 & .674 \\
\hline
\end{tabular}

Abbreviations: ILAs interstitial lung abnormalities, $R P$ radiation pneumonitis 
with SCLC having preexisting radiological ILAs must be carefully watched during chemoradiotherapy and closely monitored following TRT.

TRT is an important component of treatments for lung cancer, especially for limited-stage SCLC. However, the optimal dose and fractionation for TRT in limited-stage SCLC remain controversial; a hyperfractionated regimen ( $45 \mathrm{~Gy}$ in 30 fractions delivered as 1.5-Gy fractions twice daily, BID group) or a conventionally fractionated regimen $(60-70$ Gy in 30-35 fractions delivered as 2.0-Gy fractions once daily, QD group) has been used in routine clinical practice. Pneumonitis and dermatitis were more common in the QD group, and esophagitis was more common in the BID group [24, 25]. Possible differences in toxicities depending on RT regimen may be worth further investigation. Tsujino et al. reported that the incidence of RP was lower in the BID group than in the QD group after treatment. The incidence of $\geq$ grade 2 $\mathrm{RP}$ increased with increases in $\mathrm{V}_{20}$, and the DVH parameters (especially $V_{20}$ ) were used to predict symptomatic RP in patients undergoing BID TRT [8]. Data on the clinical and dosimetric parameters that predict RP in patients with SCLC treated with QD TRT are limited. Consequently, this retrospective analysis was conducted to contribute data on this series. No correlation was observed between the incidence of RP and dosimetric factors in the present study. The main reason for this lies in we strictly controls the limits of $\mathrm{V}_{20}, \mathrm{~V}_{5}$ and MLD. In designing a plan, we must ensure the safety of lung firstly. If the dose of lung exceeds the safety range, we will appropriately reduce the total dose.

Till now, the influence of smoking history on RP risk is unclear. The smoking history ( $\geq 40$ pack-years of smoking) was another significant clinical predictor of $\geq$ grade $3 \mathrm{RP}$ in the present study, consistent with a previous study [12]. In an analysis of 297 patients receiving SBRT for a lung tumor, pack-years of smoking was a significant predictor of RP in the multivariable analysis [10].

Concurrent chemoradiotherapy (CCRT) is recommended as a standard treatment for limited-stage SCLC. The patients with severe pulmonary complications, older age, were considered unfit to undergo concurrent chemotherapy received sequential chemoradiation in this study. Some of the patients was given sequential chemoradiation because of an advanced stage. There was no significant difference in the concurrent and sequential groups in this study. Only one retrospective study recently concluded that pulmonary fibrosis was observed significantly more often after concurrent than sequential chemoradiation in patients with limited-stage SCLC [26]. But the dose fractionation schedules were different from ours in a portion of patients. This result still needs more research to confirm the conclusion.

The clinical factors including larger gross internal tumor volume, PTV, and location of tumor were predictors of RP $[6,10]$. In the present study, neither the location of tumor nor the size of tumor (GTV) had any impact on the incidence of $\geq$ grade 2 or 3 RP. This was because the majority of SCLCs arose centrally; primary tumors located in the peripheral or lower lobes were rare. Moreover, patients with SCLC were more sensitive to chemotherapy than those with NSCLC; the irradiation field was smaller after induction chemotherapy in patients who had a partial response in GTV. The patients with a $V_{20} \geq 35 \%$ might benefit from induction chemotherapy due to an estimated reduction of RP [27].

This study had some limitations. First of all, as a retrospective study and a small sample size with short inclusion were analyzed, this study has the possibility of selection bias and confounding factors. In addition, the diagnosis of radiological ILAs was based on pretreatment CT imaging and evaluated by two experienced thoracic radiologists; the differences in subjective judgment may vary. A larger, preferable prospective data set is needed to confirm these conclusions.

\section{Conclusions}

Preexisting radiological ILAs and smoking history ( $\geq 40$ pack-years of smoking) are clinical risk factors for severe RP in patients with SCLC. Prospective studies are needed to validate these factors.

\section{Abbreviation}

AUC: Area under the curve; CCRT: Concurrent chemoradiotherapy; $\mathrm{Cl}$ : Confidence interval; CT: Computed tomography; DVH: Dose-volume histogram; FEV $_{1}$ : Forced expiratory volume in $1 \mathrm{~s}$; FVC: Forced vital capacity; HRCT: High-resolution computed tomography; ILAs: Interstitial lung abnormalities; MLD: Mean lung dose; NSCLC: Non-small-cell lung carcinoma; PE: Pulmonary emphysema; PTV: Planning target volume; RP: Radiation pneumonitis; SBRT: stereotactic body radiation therapy; SCLC: Small-cell lung cancer; TRT: Thoracic radiation therapy; $V_{10}$ : Percentage of lung volume receiving $10 \mathrm{~Gy} ; V_{20}$ : Percentage of the lung volume receiving $\geq 20 \mathrm{~Gy}$; $V_{30}$ : Percentage of lung volume receiving $30 \mathrm{~Gy}_{;} \mathrm{V}_{40}$ : Percentage of lung volume receiving $40 \mathrm{~Gy}_{;} \mathrm{V}_{5}$ : Percentage of the lung volume receiving $\geq 5 \mathrm{~Gy}$; $V_{50}$ : Percentage of lung volume receiving $50 \mathrm{~Gy}$

\section{Acknowledgments \\ The authors thank all patients who participated in the present study and colleagues at Shanghai Pulmonary Hospital, Tongji University School of Medicine. \\ Funding \\ Supported by the Science and Technology Commission of Shanghai Municipality (No. 15411962400).}

Availability of data and materials

Data sharing not applicable to this article as no datasets were generated or analyzed during the current study.

\section{Authors' contributions}

All authors contributed to the manuscript. All authors approve the final version. 
Ethics approval and consent to participate

Not applicable.

\section{Competing interests}

The authors declare that they have no competing interests.

\section{Publisher's Note}

Springer Nature remains neutral with regard to jurisdictional claims in published maps and institutional affiliations.

\section{Author details}

'The Second Affiliated Hospital of Soochow University, Suzhou, People's Republic of China. ${ }^{2}$ Department of Radiation Oncology, Shanghai Pulmonary Hospital,Tongji University School of Medicine, Zhengmin Road, Yangpu District, Shanghai 200433, People's Republic of China. ${ }^{3}$ Department of the Second Oncology, the First People's Hospital of Qinzhou, Qinzhou, People's Republic of China. ${ }^{4}$ Department of Radiation Oncology, Zhejiang Cancer Hospital, East Banshan Road, Gongshu District, Hangzhou, People's Republic of China. ${ }^{5}$ Zhejiang Key Laboratory of Radiation Oncology, Hangzhou 310022, People's Republic of China.

Received: 27 January 2018 Accepted: 16 April 2018

Published online: 02 May 2018

\section{References}

1. van Meerbeeck JP, Fennell DA, De Ruysscher DK. Small-cell lung cancer. Lancet. 2011;378:1741-55.

2. Rudin CM, Ismaila N, Hann CL, et al. Treatment of small-cell lung Cancer: American Society of Clinical Oncology endorsement of the American College of Chest Physicians Guideline. J Clin Oncol. 2015;33:4106-11.

3. Turrisi AT 3rd, Kim K, Blum R, et al. Twice-daily compared with once-daily thoracic radiotherapy in limited small-cell lung cancer treated concurrently with cisplatin and etoposide. N Engl J Med. 1999;340:265-71.

4. Faivre-Finn C, Snee M, Ashcroft L, et al. Concurrent once-daily versus twicedaily chemoradiotherapy in patients with limited-stage small-cell lung cancer (CONVERT): an open-label, phase 3, randomised, superiority trial. Lancet Oncol. 2017;18:1116-25.

5. Schild SE, Bonner JA, Shanahan TG, et al. Long-term results of a phase III trial comparing once-daily radiotherapy with twice-daily radiotherapy in limited-stage small-cell lung cancer. Int J Radiat Oncol Biol Phys. 2004; 59:943-51.

6. Palma DA, Senan S, Tsujino K, et al. Predicting radiation pneumonitis after chemoradiation therapy for lung cancer: an international individual patient data meta-analysis. Int J Radiat Oncol Biol Phys. 2013;85:444-50.

7. Giuliani ME, Lindsay PE, Kwan JY, et al. Correlation of dosimetric and clinical factors with the development of esophagitis and radiation pneumonitis in patients with limited-stage small-cell lung carcinoma. Clin Lung Cancer. 2015;16:216-20.

8. Tsujino K, Hirota S, Kotani Y, et al. Radiation pneumonitis following concurrent accelerated hyperfractionated radiotherapy and chemotherapy for limited-stage small-cell lung cancer: dose-volume histogram analysis and comparison with conventional chemoradiation. Int J Radiat Oncol Biol Phys. 2006;64:1100-5.

9. Jin H, Tucker SL, Liu HH, et al. Dose-volume thresholds and smoking status for the risk of treatment-related pneumonitis in inoperable non-small cell lung cancer treated with definitive radiotherapy. Radiother Oncol. 2009;91:427-32.

10. Baker R, Han G, Sarangkasiri S, et al. Clinical and dosimetric predictors of radiation pneumonitis in a large series of patients treated with stereotactic body radiation therapy to the lung. Int J Radiat Oncol Biol Phys. 2013;85:190-5

11. Zhang XJ, Sun JG, Sun J, et al. Prediction of radiation pneumonitis in lung cancer patients: a systematic review. J Cancer Res Clin Oncol. 2012;138: 2103-16.

12. Monson JM, Stark P, Reilly JJ, et al. Clinical radiation pneumonitis and radiographic changes after thoracic radiation therapy for lung carcinoma. Cancer. 1998:82:842-50.

13. Jin GY, Lynch D, Chawla A, et al. Interstitial lung abnormalities in a CT lung cancer screening population: prevalence and progression rate[J]. Radiology. 2013;268(2):563.
14. Le Jeune I, Gribbin J, West J, et al. The incidence of cancer in patients with idiopathic pulmonary fibrosis and sarcoidosis in the UK. Respir Med. 2007; 101:2534-40.

15. Choi WI, Park SH, Park BJ, Lee CW. Interstitial lung disease and lung Cancer development: a 5-year Nationwide population-based study. Cancer Res Treat. 2018:50:374-81.

16. Nishino M, Cardarella S, Dahlberg SE, et al. Interstitial lung abnormalities in treatment-naïve advanced non-small-cell lung cancer patients are associated with shorter survival[J]. Eur J Radiol. 2015;84(5):998.

17. Doyle TJ, Hunninghake GM, Rosas IO. Subclinical interstitial lung disease: why you should care. Am J Respir Crit Care Med. 2012;185:1147-53.

18. Ozawa $Y$, Abe T, Omae $M$, et al. Impact of preexisting interstitial lung disease on acute, extensive radiation pneumonitis: retrospective analysis of patients with lung Cancer. PLoS One. 2015;10:e0140437.

19. Yamaguchi $\mathrm{S}$, Ohguri $\mathrm{T}$, Ide $\mathrm{S}$, et al. Stereotactic body radiotherapy for lung tumors in patients with subclinical interstitial lung disease: the potential risk of extensive radiation pneumonitis. Lung Cancer. 2013;82:260-5.

20. Ueki N, Matsuo Y, Togashi Y, et al. Impact of pretreatment interstitial lung disease on radiation pneumonitis and survival after stereotactic body radiation therapy for lung cancer. J Thorac Oncol. 2015;10:116-25.

21. Yamashita H, Kobayashi-Shibata S, Terahara A, et al. Prescreening based on the presence of CT-scan abnormalities and biomarkers (KL-6 and SP-D) may reduce severe radiation pneumonitis after stereotactic radiotherapy. Radiat Oncol. 2010;5:32

22. Travis WD, Costabel U, Hansell DM, et al. An official American Thoracic Society/European Respiratory Society statement: update of the international multidisciplinary classification of the idiopathic interstitial pneumonias. Am J Respir Crit Care Med. 2013;188:733-48.

23. Raghu G, Collard HR, Egan JJ, et al. ATS/ERS/JRS/ALAT committee on idiopathic pulmonary fibrosis. An official ATS/ERS/JRS/ALAT statement: idiopathic pulmonary fibrosis: evidence-based guidelines for diagnosis and management. Am J Respir Crit Care Med. 2011;183(6):788-824.

24. Gazula A, Baldini EH, Chen A, Kozono D. Comparison of once and twice daily radiotherapy for limited stage small-cell lung cancer. Lung. 2014 192:151-8.

25. Han D, Hao S, Tao C, et al. Comparison of once daily radiotherapy to $60 \mathrm{~Gy}$ and twice daily radiotherapy to 45 Gy for limited stage small-cell lung cancer. Thorac Cancer. 2015;6:643-8.

26. Sas-Korczyńska B, Łuczyńska E, Kamzol W, et al. Analysis of risk factors for pulmonary complications in patients with limited-stage small cell lung cancer : a single-Centre retrospective study. Strahlenther Onkol. 2017:193(2):141-9.

27. Amin NP, Miften M, Kavanagh B, et al. Impact of induction chemotherapy on estimated risk of radiation pneumonitis in small cell lung cancer. J Thorac Oncol. 2011;6:1553-62.

\section{Ready to submit your research? Choose BMC and benefit from:}

- fast, convenient online submission

- thorough peer review by experienced researchers in your field

- rapid publication on acceptance

- support for research data, including large and complex data types

- gold Open Access which fosters wider collaboration and increased citations

- maximum visibility for your research: over $100 \mathrm{M}$ website views per year

At BMC, research is always in progress.

Learn more biomedcentral.com/submissions 